\title{
A rare complication of ureteral stent removal: Questions
}

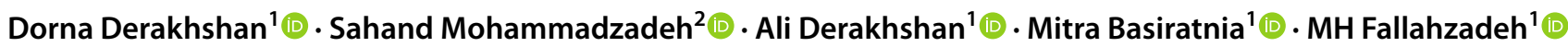

Received: 1 July 2021 / Accepted: 2 July 2021 / Published online: 6 October 2021

(c) IPNA 2021

Keywords Adolescent $\cdot$ Ureteropelvic junction obstruction $\cdot$ Abdominal pain $\cdot$ Fever

\section{Case presentation}

A 15-year-old girl, with a known case of corrected ureteropelvic junction obstruction (UPJO), was admitted to the pediatric nephrology ward due to acute onset fever and abdominal pain. The patient has been apparently well till 6 months prior to admission when following investigations for vague abdominal pain; severe right-sided hydronephrosis associated with severe cortical thinning was detected on ultrasound. Diuretic renal scintigraphy with Tc99m-DTPA revealed decreased perfusion and function of the right kidney with no response to furosemide injection suggestive of significant mechanical obstruction. Differential renal uptake was $41 \%$ and $59 \%$ in the right and left kidneys, respectively. The patient underwent right dismembered pyeloplasty, and a double J (DJ) stent was inserted into the right ureter and pelvis. Due to the COVID-19 pandemic, the patient postponed DJ stent removal to 5 months after pyeloplasty. Two days after DJ removal, the patient developed fever, chills, severe flank pain, and vomiting and was admitted with the clinical diagnosis of urosepsis.

In the physical examination, the patient appeared toxic; vital sign examination revealed fever (temperature, 39.5 ${ }^{\circ} \mathrm{C}$ ), tachycardia (heart rate $125 / \mathrm{min}$ ), and hypotension (blood pressure, $85 / 50 \mathrm{mmHg}$ ). Abdominal examination revealed a very severe flank tenderness in the right quadrant area. The initial lab results included blood

The answers to these questions can be found at https://doi.org/10 1007/s00467-021-05264-9.

Dorna Derakhshan

Derakhshad@sums.ac.ir

1 Shiraz Nephro-Urology Research Center, Shiraz University of Medical Sciences, Shiraz, Iran

2 Department of Pathology, Shiraz University of Medical Sciences, Shiraz, Iran urea nitrogen, $50 \mathrm{mg} / \mathrm{dl}$; creatinine, $2.04 \mathrm{mg} / \mathrm{dl} ; \mathrm{Na}, 128$ $\mathrm{mmol} / \mathrm{L}$; K, $2.8 \mathrm{mmol} / \mathrm{L}$; white blood cell count, $18.110^{3} /$ $\mathrm{ml}$; hemoglobin, $8.6 \mathrm{~g} / \mathrm{dl}$; platelets, $120 \times 10^{3} / \mathrm{ml}$; and C-reactive protein $>150 \mathrm{mg} / \mathrm{L}$. Urine microscopy showed abundant white blood cells and 20-25 red blood cells per high-power field. Initial resuscitation with intravenous fluid was undertaken, and antibiotic therapy with meropenem was started after obtaining the urine and blood cultures. Ultrasound study of the abdomen and pelvis revealed mildly increased parenchymal echogenicity in both kidneys.

On the subsequent day, her general condition deteriorated, so an emergency abdominal and pelvic computed tomography (CT) scan was done, which demonstrated marked enlargement of the right kidney with intraparenchymal, perinephric, and pararenal air (Fig. 1). The patient underwent a right nephrectomy. The histopathologic results are demonstrated in Fig. 2. Vancomycin and metronidazole were added to the antibiotic regimen. The blood and urine cultures were positive for E. coli, and based on the antibiogram, meropenem was replaced by colistin. The patient's overall condition improved dramatically after nephrectomy and fever abated gradually. Intravenous antibiotic therapy was continued for 2 weeks following nephrectomy. The patient's kidney function improved during this period of admission, and the creatinine level was $0.8 \mathrm{mg} / \mathrm{dl}$ at the time of discharge from the hospital. 
Fig. 1 Coronal and axial images demonstrate significant enlargement of the right kidney (180 $\mathrm{mm}$ ) with severe hydronephrosis and cortical thinning
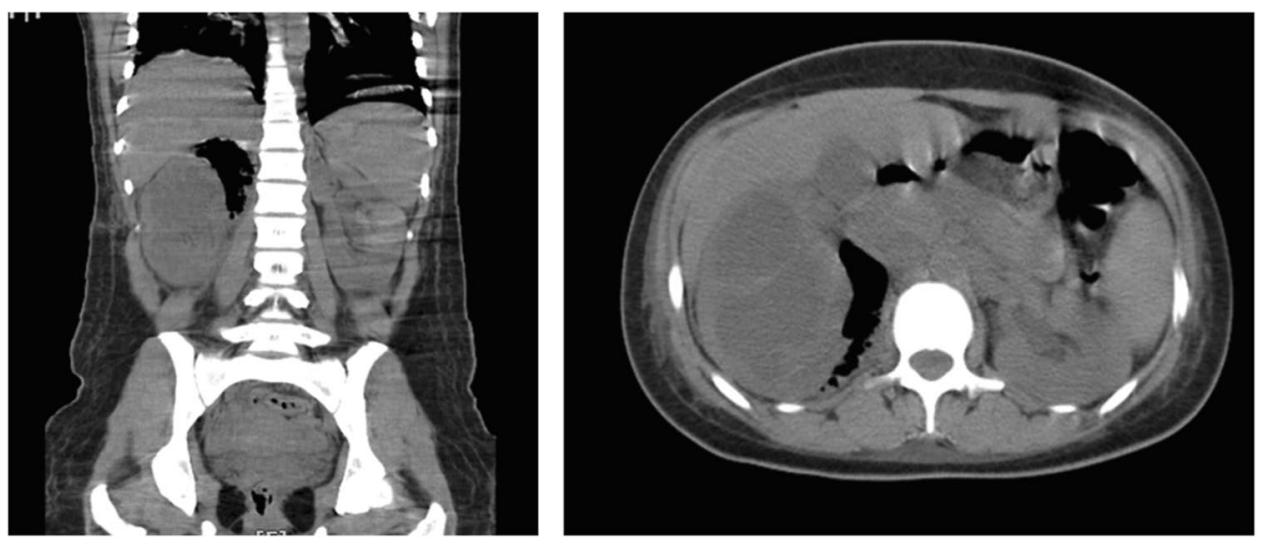

Fig. 2 A Abscess cavities of polymorphonuclear cells in the pelvis extending into renal tissue (H\&E, 4X); $\mathbf{B}$ acute and chronic inflammatory infiltration in renal parenchyma $(\mathrm{H} \& \mathrm{E}$, $\times 40)$; $C$ intratubular WBC casts with infiltration of inflammatory cells in renal parenchyma (H\&E, 40X)
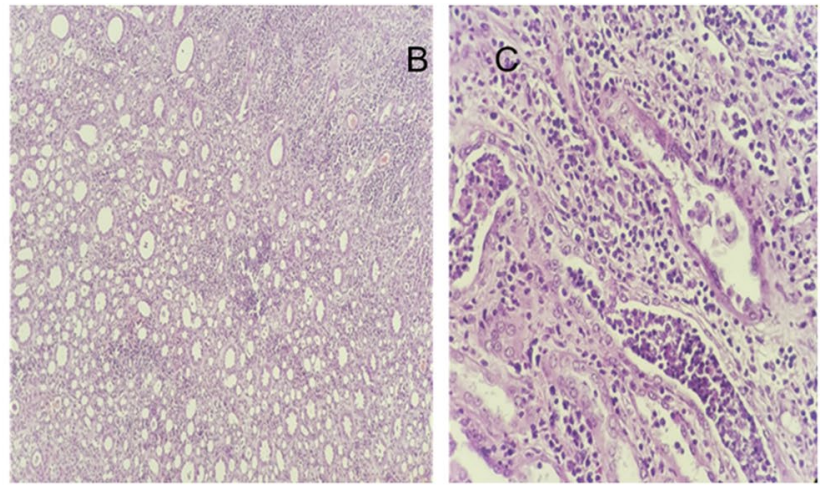

\section{Questions}

1) What is the most likely diagnosis for this patient?

2) What are the risk factors for this condition?

3) What are the diagnostic modalities?

4) What are the management strategies?

Author contribution $\mathrm{DD}, \mathrm{AD}, \mathrm{MB}$, and MHF made the diagnosis and drafted the manuscript. SM provided the pathologic reports and figures. All authors read and approved the final version of the manuscript.

Data availability The datasets used and/or analyzed during the current study are available from the corresponding author on reasonable request.

\section{Declarations}

Consent to participate Consent was obtained from the parents of the patient regarding the publication of this case report.

Competing interests The authors declare no competing interests.

Publisher's note Springer Nature remains neutral with regard to jurisdictional claims in published maps and institutional affiliations. 